\title{
EL CRISTIANISMO DE F. M. DOSTOIEVSKI Y SU CORRESPONDENCIA CON LA EXPERIENCIA DEL AMOR EN IGNACIO DE LOYOLA
}

\author{
MANUEL DÍAZ MÁRQUEZ \\ Fundación SAFA, Andalucía
}

\begin{abstract}
RESUMEN. Este artículo va a estar centrado en una cuestión fundamental: ¿pueden compararse las visiones éticas de Dostoievski e Ignacio de Loyola? Haciendo una revisión pormenorizada de las bases existenciales dostoievskianas, podremos comprobar cómo la vida de Ignacio de Loyola parece coincidir con la hoja de ruta que, más tarde, elaboraría Dostoievski en sus obras en busca de una plenitud humana. El hombre pleno propuesto por el autor ruso es un reflejo del San Ignacio que conocemos por su Autobiografía, un personaje que pasó de los confines existenciales más arraigados en el yo a una vida por y para los demás basada en una idea fundamental: «En todo, amar y servir».
\end{abstract}

PALABRAS CLAVE: Dostoievski, Ignacio de Loyola, Ética, Existencia, Dios, Cristo, Jesuitas, Compañía de Jesús, Amor, Hombre pleno.

ABSTRACT. This article is going to focus mainly on a question: ¿can Dostoyevsky's and Ignatius of Loyola's ethical visions be compared? By means of a detailed revision of the Dostoyevskian existential basis, we will be able to prove how Ignatius of Loyola's life seems to match the path that Dostoyevsky will later set in his works when looking for human plenitude. The fulfilled man, as proposed by the Russian author, mirrors the figure of Saint Ignatius that we know thanks to his Autobiografía. He is a character that moved from the existential boundaries rooted in the concept of the self to a life lived for the others based on a main idea: «In all things, to love and to serve».

KEY WORDS: Dostoyevsky, Ignatius of Loyola, Ethics, Existence, God, Christ, Jesuits, The Society of Jesus, Love, Fulfilled Man.

\section{INTRODUCCIÓN}

Somos conscientes de que la comparación entre la compleja manera de entender el cristianismo de Fiódor Dostoievski y la visión ético-existencial propuesta por la espiritualidad de Ignacio de Loyola, y la Compañía de Jesús, puede resultar, cuanto menos, sorprendente. Sin embargo, si nos adentramos en las bases más profundas de ambas posturas, podremos ver que dicha conexión es claramente detectable. Y esto sucederá, fundamentalmente, si lo analizamos desde la figura de San Ignacio de Loyola, quien experimentó en su propia carne un desarrollo existencial casi idéntico al que, muchos años más tarde, Dostoievski propusiera como el modelo de búsqueda de la plenitud humana.

Desde siempre se ha catalogado a Dostoievski como el autor del sufrimiento por antonomasia. La analogía del sufrimiento de Cristo con el sufrimiento de los personajes dostoievskianos es una constante manida que puede leerse en la mayoría de los trabajos de investigación sobre el autor. El sufrimiento y la sombra parecen las únicas bases defendidas por Dostoievski según la mayoría de sus intérpretes tradicionales. Y, desde luego, no son afirmaciones descabelladas. 
Y es que parece evidente, a ojos de cualquier lector, que Fiódor Dostoievski no es un autor excesivamente luminoso en cuanto a su visión de la vida, del hombre y la sociedad. De hecho, son muchos los especialistas que destacan en el genio ruso solamente sus aspectos más oscuros: la tragedia existencial, la naturaleza atormentada del hombre ${ }^{1}$ y el sufrimiento como única vía de redención posible. Pero, ¿es esto Dostoievski? O, lo que quizá puede ser una cuestión más certera, ¿es sólo esto Dostoievski?

Ya el mismo autor dista mucho de lo que podría denominarse un ser luminoso. Sólo hace falta contemplar cualquiera de sus retratos para hallar una mirada atormentada, enmarcada en la faz de un personaje sombrío y taciturno. Así es como se nos ha solido presentar por lo general tanto al autor como a sus obras. Es cierto que Dostoievski vivió atormentado por muchos demonios, tanto internos como externos. Su vida, como ya sabemos, fue un cúmulo de sufrimientos que lo fueron empujando a lo largo de un tránsito existencial en el que escribía a contrarreloj mientras eludía a los acreedores. Cuando vemos la imagen de Dostoievski, no es difícil comprender que estamos viendo la imagen del espíritu asediado, del falso conspirador desterrado a Siberia tras librarse en el último momento de ser fusilado, del hombre que sufre hemorroides, del eterno deudor, del sospechoso de la violación de una menor (que llegó a suicidarse por este hecho), en definitiva, estamos viendo la imagen de la oscuridad, de los aspectos más sombríos de la humanidad. ¿Qué eticidad podrá transmitirnos este tipo de autor? ¿Cómo podemos argumentar que su base es un amor luminoso como el que propone la ética jesuítica?

Realmente, la obra de Dostoievski va a estar muy por encima de esa negatividad superficial. Y he aquí el punto de inflexión de nuestra investigación: centrarse en su obra, en lo que realmente nos dice Dostoievski. Sus personajes y sus historias nos transmiten un mensaje de esperanza, proporcionándonos una guía en la búsqueda de la plenitud humana. Y esta guía tendrá una relación muy estrecha con algunos conceptos éticos jesuíticos fundamentales (especialmente los relacionados con la luminosidad, el amor y la idea de un Nosotros que va a incluir a la humanidad en conjunto). Por ello, vamos a partir de que hay dos formas de entender a Dostoievski, una dirigida exclusivamente hacia el autor

\footnotetext{
1 Hablamos aquí de un hombre de género masculino, ya que la mujer no es más que una tragedia interior del varón, como diría NiKolay BERDIAEv en su obra El espíritu de Dostoyevski: «El amor en Dostoyevski es exclusivamente dionisíaco; atormenta al hombre. El camino del hombre en Dostoyevski es el camino del sufrimiento. Para él, el amor es una erupción volcánica, una explosión de dinamita en la naturaleza apasionada del hombre. [...] En el amor ruso hay algo de penoso y doloroso, de inquieto y, a menudo, de monstruoso. [...] Veremos que, a Dostoyevski, la mujer le interesa exclusivamente como un momento en el destino del hombre, en el camino de la persona. El alma humana es, ante todo, el espíritu del varón. El principio femenino es solamente un problema interior en la tragedia del espíritu viril, una seducción interior. [...] En ninguna parte se encuentra una imagen hermosa del amor, ni tampoco una imagen femenina que tenga un significado independiente. Siempre le atormenta el destino trágico del hombre. La mujer es solamente una tragedia interior del varón» (trad. Olga Trankova, Editorial Nuevo Inicio, Granada, 2008, pp. 119-121)
} 
(donde nos encontraremos su propia espiritualidad, su visión del sufrimiento y, en definitiva, esa oscuridad que a tantos lectores no especializados llega a abrumar), y otra dirigida hacia su obra en general, centrada en observar qué puede transmitirnos en nuestro mundo actual. La inmensa mayoría de las investigaciones sobre Dostoievski han ido hacia adentro, hacia la persona, hacia la interioridad del creador. Nosotros, sin embargo, vamos a destacar lo que puede ofrecernos su obra como lectores occidentales del siglo XXI: unas reflexiones éticas y existenciales en las que el amor tendrá un papel predominante y en las que la mujer (muy al contrario de lo que pensara Berdiaev, como hemos visto en la anterior nota al pie), será fundamental.

Pero, ¿qué tendrá todo esto que ver con Ignacio de Loyola? ¿Qué sentido puede tener unir aquí a Dostoievski y al padre de la Compañía de Jesús? ¿Cómo podemos poner de acuerdo al padre del Gran Inquisidor ${ }^{2}$ con la Iglesia? La respuesta es sencilla: Ignacio de Loyola experimentó una transformación propia de un personaje dostoievskiano. Su vida siguió casi paso a paso la propuesta dostoievskiana hacia el hombre pleno. Las profundas bases existenciales ineludibles según Dostoievski para alcanzar la Verdad fueron ya vividas por San Ignacio y dejadas por escrito, como veremos más adelante, en sus obras. Sin lugar a dudas, el uso práctico de la razón en Dostoievski sigue las mismas pautas que anteriormente desarrollara Ignacio de Loyola como proyecto vital propio. Esta va a ser la tesis que defenderemos.

\section{LA IMPORTANCIA DEL AMOR EN EL ENTRAMADO EXISTENCIAL DOSTOIEVSKIANO}

Como ya se expuso en el ensayo La luz en Dostoievski ${ }^{3}$, una revisión pormenorizada de la obra de nuestro autor puede dar como resultado la extracción de todo un sistema existencial que Dostoievski comenzó a fraguar ya desde su Pobres Gentes. Si vemos su obra como conjunto, nos encontraremos con una estructura que la recorre de principio a fin y que nos muestra diversas formas de estar en el mundo, siempre bajo la base subyacente de un acuerdo social creado por el mero interés común. Aquí es donde toma base la ética dostoievskiana.

La sociedad es un paisaje en Dostoievski, un marco, un decorado ineludible. Es el lugar donde las cosas pasan, donde las existencias se desenvuelven,

2 En Los Hermanos Karamázov, Dostoievski escribe su famosa Parábola del Gran Inquisidor, en la que, en boca del agnóstico Iván Karamázov, nos cuenta cómo Cristo, en su segunda llegada al mundo, es apresado por la Inquisición y tiene una conversación en Sevilla con el cardenal gran inquisidor. En esta conversación, el cardenal le cuenta que la Iglesia vive del miedo del vulgar populacho, basado en el milagro y el misterio. Por este motivo expulsará a Cristo de la ciudad diciéndole que no vuelva, pues no se le necesita. Es una magistral parábola sobre la enorme separación entre el mensaje de Cristo y la Iglesia católica, que, a ojos de Dostoievski, ha degenerado hasta unos niveles deleznables.

3 Díaz Márouez, M., La luz en Dostoievski, Ediciones Casas, Sevilla, 2012. 
sufren, triunfan... Es contra la sociedad contra la que se delinque, también será la sociedad la que pueda redimir en último término los crímenes del individuo. Dostoievski va a presentar a esta sociedad como una masa. La masa es la que atormenta a Goliadkin en El Doble, es la que hace ocultarse al hombre del subsuelo, la que empuja al crimen a Raskólnikov, la que inflama los corazones de los Demonios. Pero es también en la masa donde Dostoievski ve el punto de partida para alcanzar la plenitud existencial. Un camino con infinitas rendijas, con múltiples callejones sin salida, pero que siempre se presenta enfocado (si observamos su obra como un todo) hacia la idea del amor como la verdadera esperanza del ser humano (y no como una mera pasión dionisíaca, como afirmaba Berdiaev).

Toda individualidad humana se enfrenta en mayor o menor medida y de manera inexcusable a esa masa social. El individuo va a tener siempre como referencia a la masa, bien para aceptarla e intentar dominarla, bien para despreciarla. Y esta no es más que un conjunto de individuos que actúan de forma independiente respecto a cada uno de ellos por separado. Esta es la sociedad que define Dostoievski (porque es la que sufre en su propia carne), y será la sociedad que pretende cambiar de una manera utópica, resolviendo finalmente conclusiones muy similares a las que defiende la Compañía de Jesús. Se trata de cambiar una sociedad basada en la masa informe y agresiva, transmutándola hacia otro tipo de sociedad basada en el sentimiento de comunidad y regida por el principio irrenunciable del amor.

La obra de Dostoievski no es más que un compendio sobre los modos de relación que puede haber entre individuo y sociedad. Podemos encontrar varios grados ${ }^{4}$ :

El más básico será el de la inmersión total en dicha masa. Dostoievski nos muestra individuos cuyas únicas aspiraciones son las de pasar desapercibidos y cubrir sus necesidades primarias (o sea, las necesidades físicas, las pulsiones elementales). Los sujetos que consiguen satisfacer medianamente estos objetivos primarios serán felices (muy en línea con la felicidad que Kant distinguiera de la felicidad digna). Estos serán los hombres-masa orteguianos que tan presentes están en la obra de nuestro autor. Y este es el escenario en el que todo pasa, el telón de fondo en el que las cosas realmente importantes van a tener lugar.

"¿Cuántos hombres hay que no piensan, sino que viven de ideas que otros les dan ya hechas? Pero aquí no solo se vive de ideas hechas, sino hasta de dolor hecho (y además, sin cultura)» ${ }^{5}$.

4 Esta escala puede encontrarse desarrollada en profundidad y acompañada de ejemplos directos de los textos dostoievskianos en mi obra Fiódor Mijáilovich Dostoievski: existencia, sociedad y verdad, Universidad de Sevilla, Sevilla, 2011.

5 Dostoievski, F. M., o. c., Del Dostoievski inédito. Pensamientos anotados, trad. Rafael Cansinos-Assens, Aguilar, Madrid, 1992, p. 707. Todas las obras dostoievskianas que se citen en adelante, salvo que se mencione lo contrario, pertenecerán a esta edición de sus obras completas. 
Una variante de este tipo de personalidad es la del individuo que no consigue encontrar el sitio que desea dentro de esa masa. Son personas más débiles, que no consiguen satisfacer esas necesidades básicas (alimenticias, sexuales...). Los miembros de la misma masa a la que quieren pertenecer les pisan el terreno y les impiden el éxito. Y esto no se hace por crueldad, sino por propia selección natural. El débil se topa con una masa hostil que, sin tener conciencia de ello, coarta constantemente incluso sus intentos de ser meramente uno más. Es lo que da como resultado al paria, al individuo excluido. Es una de las formas de vida más infructuosas, en la que se sigue siendo masa y, a la postre, desdichado. No se aporta nada a la sociedad, ni tampoco a la propia vida (el hombre-masa, al menos, se siente satisfecho con su vida). La característica principal en este estadio existencial será la infelicidad, la misma en la que se encuentra Goliadkin en El Doble.

«Quien estaba más cerca de él era un oficial del ejército, alto y gallardo, junto al cual el señor Goliadkin se sentía como un mísero insecto » ${ }^{6}$.

Otra posible respuesta será la de rebelarse frente al propio entorno. Igualmente, podemos destacar dos formas de rebelión existencial. La primera de ellas será una rebelión pasiva. Quien se encuentra en este estado existencial basará su vida en la mera crítica de su entorno, será la figura del antihéroe, del hombre del subsuelo. Un antihéroe se define más por lo que no es que por lo que concretamente es. Rechazará todas las reglas de cortesía, buen gusto, modas... en definitiva, lo políticamente correcto, por considerarlo un burdo invento de una sociedad despreciable. El rebelde pasivo ve al hombremasa desde una perspectiva de superioridad, defiende su individualidad y se enfrenta a lo común. Pero, a su vez, teme a la masa porque conoce su gran poder. El antihéroe sabe que esa masa puede aplastarlo en cualquier momento por enfrentarse a sus principios de estabilidad. Por eso mantiene una distancia prudencial y ejercerá su rebelión de modo pasivo, resguardado en la intimidad. La existencia de este tipo de individualidades estará marcada por el odio, que es el que da realmente un sentido a sus vidas. La gran diferencia con los grados anteriores es que aquí sí estamos encontrando ya una individualidad definida, que se distingue de las demás. Y esto será fundamental para llegar a una comprensión profunda de la realidad.

«En toda novela hay que presentar a un héroe, y aquí hállanse expresamente reunidos todos los rasgos de un antihéroe; y, sobre todo, mi relato ha de producir una impresión desagradable, porque todos, más o menos, hemos perdido la costumbre de la vida hasta tal punto, que a veces sentimos una suerte de asco por la vida verdadera, y por eso nos sienta mal el que nos la recuerden. Hemos llegado a considerar la vida viva como un trabajo, casi como un empleo, y todos somos en nuestro interior de parecer que es mejor vivir en los libros» ${ }^{7}$.

6 Dostoievski, o. c., El Doble, p. 52.

7 Dostoievski, o. c. Memorias del subsuelo, p. 1522. 
Un paso adelante será llegar a una rebelión activa. Este tipo de individualidad ya actúa, intenta cambiar la realidad, marcar su entorno. Aquí sí podemos observar una individualidad fuerte, conocedora de su poder y protagonista de su propia vida. Al igual que el antihéroe, el rebelde activo también aborrece a la masa, pero enfoca su enfrentamiento de una manera radicalmente diferente. Si bien el antihéroe se queda en la mera crítica y en el odio más profundo, el individuo colocado en esta escala optará por la acción para cambiar su entorno. Son los que intentan romper lo establecido y dictar la dirección hacia la que los demás deben dirigirse. Si una de estas individualidades triunfa, adquirirá tintes heroicos; pero si fracasa, se convertirá en un villano o en un loco. Sólo aquél que esté dispuesto a asumir las consecuencias de sus actos se arriesgará a asomarse a este abismo existencial. Este será el punto cumbre dentro del desarrollo de la individualidad humana que podemos encontrar en Dostoievski. A partir de aquí entrará en juego la importancia del otro como parte de uno mismo, que es lo que muchos de los intérpretes de Dostoievski no han sabido destacar.

"La persona «extraordinaria» tiene el derecho... o sea, no un derecho oficial, sino un derecho propio, de saltar por encima de ciertos obstáculos, y aun eso tan solo en el caso de que así lo exija la realización de una idea suya, en ocasiones salvadora, quizá, para toda la humanidad $»^{8}$.

Así, el individuo encontrará en Dostoievski dos vías de sociabilización: una externa y estéril (impuesta por la coacción social), y otra interna y fructífera, que va a llevarse a cabo reflexivamente. El hombre comienza a sociabilizarse de manera reflexiva cuando logra comprender que los demás forman parte de él, al igual que él forma parte de los demás. Y el nexo de unión entre individuo y sociedad residirá en el amor. Cuando una persona siente amor por otra, se transforma. Aquí es donde está el paso ineludible para poder alcanzar a Dios. Esa primigenia admisión de otro individuo como parte de la propia mismidad será la que nos muestre el camino hacia un grado superior de existencia. El enamorado es quien encuentra en primer lugar ese sentimiento que lo hará capaz de hacer propio lo ajeno. Como ejemplo más claro tendremos a Raskólnikov en Crimen y Castigo. Raskólnikov resucita cuando se enamora de Sonia (según palabras de nuestro autor) y vuelve a sumergirse en los cauces sociales de los que se había autoexpulsado con su crimen'. Para Dostoievski el amor es el instrumento más útil en el proceso de humanización de la persona. Sólo ese sentimiento de enamoramiento será capaz de encauzar al hombre en la dirección hacia la plenitud humana propuesta y buscada por nuestro autor. $\mathrm{Ni}$ la moralidad impuesta, ni el castigo, ni el desprecio... nada de esto hará al hombre, desde el punto de vista dostoievskiano, cambiar su pensamiento

\footnotetext{
Dostoievski, o. c., Diario de un escritor, p. 363.

Cuando Sonia visita a Raskólnikov en la cárcel y él se percata de que está enamorado de ella, podemos leer en Crimen y Castigo: «Pero Raskólnikov había resucitado, y él lo sabía y lo sentía en todo su ser. Y Sonia..., Sonia no vivía sino la vida de Raskólnikov» (p. 542).
} 
o domar ese sentimiento de individualidad radical y predominante. Sólo el amor puede lograr que el hombre se convierta en un miembro legítimo de la sociedad.

\section{La CONEXIÓN CON IGNACIO DE LOYOLA}

El enamorado no se siente completo sin la otra persona, completa su existencia en base a una existIncia externa, al igual que el andrógino platónico. Esta será la base del amor global que sería el último estadio en esta progresión. Para alcanzar la plenitud existencial será necesario que el individuo experimente ese sentimiento no ya fraternal, sino amoroso, hacia el resto de la humanidad: el hombre pleno ha de estar enamorado de la humanidad. Y queremos decir un enamoramiento de raíz, un sentimiento de pertenencia mutua en el conjunto de todas las individualidades que forman al ser humano en general. Sólo cuando un hombre entiende que su existencia se basa en la de los demás, sólo cuando un hombre lucha con una certeza inquebrantable de que el conjunto al que defiende forma parte de su mismo ser, estaremos frente a una existencia plena. Parece inevitable recordar aquí la famosa frase de Ignacio de Loyola: En todo amar y servir ${ }^{10}$. En el momento en el que el ser humano consiga percatarse en conjunto de esta realidad, el hombre en general se hará pleno, y estaremos hablando, a ojos también de Dostoievski, de una auténtica nueva y plena generación humana, totalmente superior a la anterior. Podemos leer en El sueño de un hombre ridículo:

«Diré algo más: ¡que sea cierto que nunca se cumpla y que no exista nuestro paraíso (eso ya lo entendí yo), pero, a pesar de todo, predicaré! No obstante, sería tan sencillo: en un día, en tan sólo una hora, todo podría hacerse realidad. Lo más importante es que ames a tus semejantes como a ti mismo, y eso es lo fundamental; creo que no se necesita nada más: al instante encontrarías cómo ordenar tu existencia. ¡Además, sólo se trata de una verdad antiquísima, leída y repetida billones de veces, pero que no terminó de arraigar! Porque «la conciencia de la vida está por encima de la vida misma, el conocimiento de las leyes de la felicidad excede a la propia felicidad». ;Contra eso es contra lo que hay que luchar! Y yo lo haré. Si todos lo desearan, las cosas cambiarían al instante» ${ }^{11}$.

Como podemos ver, toda la problemática existencial propuesta por Dostoievski tiene como meta la consecución de un amor global que coloque al todo en el mismo plano existencial del individuo en concreto. El éxito de la existencia humana residirá en que el individuo asuma al resto de la humanidad como parte de su mismo ser, y que cada uno de los restantes individuos tomen a

10 Ignacio De Loyola, Ejercicios Espirituales, Editorial Sal Terrae, Santander, 1990, p. 134.

11 Dostoievski, Cuentos, El sueño de un hombre ridículo, trad. Bela Martinova, Ediciones Siruela, S. A., Barcelona, 2009, p. 498. 
este individuo (y a todos los demás) también como partes del mismo conjunto. Este conjunto se creará desde la idea de ese Nosotros del que venimos hablando. El individuo tiene que amar al resto de la humanidad tanto como a sí mismo. Sólo desde la inercia de un amor global podrá alcanzarse la idea del hombre pleno que busca Dostoievski.

Y entendamos que lo que Dostoievski propone con esto no es una existencia dócil, débil, basada en el sometimiento de cada individuo a su entorno social (tampoco es lo que propone la ética jesuítica). Más bien es todo lo contrario. Dostoievski defiende la fuerza de la libertad humana; pero también nos advierte que, hasta que esa libertad no busque, por sí misma focalizar su fuerza a través del amor a los demás, el hombre no obtendrá una existencia verdadera. Nuestro autor nunca aprobará una existencia sometida, sino que buscará un cambio natural en el pensamiento, alcanzado de manera individual y convencida. Por eso era tan importante para él dejar asentadas las bases de una individualidad fuerte. Por eso, para que un jesuita pueda ayudar a los demás, ha de ayudarse previamente a sí mismo.

Un hombre que carece de libertad carecerá de personalidad y, como dice Buytendijk, de dignidad ${ }^{12}$; es por esto por lo que los personajes dostoievskianos pugnan constantemente por el reconocimiento propio y ajeno de esa libertad para pensar y actuar. Y en esa búsqueda se aloja el grueso de las dificultades que presenta una vida en sociedad. La vida, en su más primitivo aspecto, siempre se despliega en una constante lucha por la primacía de las distintas individualidades. El hombre, en principio, sólo consigue ejercer su libertad sometiendo la de los demás. Es la ley del más fuerte, que hace que el individuo sólo pueda desarrollar su existencia a golpe de garrote. Esto llevará a que, en la vida en sociedad, se despliegue igualmente una violencia primigenia que se irá limando con el avance de la civilización. Las bases jesuíticas son idénticas: para amar y servir a los demás hay que partir de una individualidad profundamente consciente, es fundamental un proceso introspectivo radical antes de poder abarcar la tarea de servir a los demás. Antes de amar a los demás hay que aprender a amarse a uno mismo.

Ante esto, no es posible evitar la tentación de realizar un paralelismo entre la progresión existencial que podemos extraer de la obra dostoievskiana (vista en su conjunto), con la misma vida de Ignacio de Loyola. Como él mismo cuenta en su autobiografía:

12 BuytendiJK, Fr. J. J., La psicología de la novela. Estudios sobre Dostoievski, trad. Fernando Vela, Ediciones Carlos Lohlé, Buenos Aires, 1961: «Cada uno de los seres humanos que Dostoievski convoca ante nosotros es libre y esta libertad constituye su propia dignidad. De este ser-digno y de la indignidad de todo nexo con las pasiones y la necesidad, el dolor y la muerte, brota la problemática que agita, inquieta, desgarra y por fin derriba o mantiene al ser humano que vive en estas novelas» (p. 41). 
«Fue un hombre dado a las vanidades del mundo y principalmente se deleitaba en el ejercicio de armas con un grande y vano deseo de ganar honra» ${ }^{13}$.

Vemos en el mismo Ignacio de Loyola la experiencia de un sujeto que, en un primer momento de su progresión existencial, siente como central y prioritario el hecho de su misma individualidad radical. Ignacio se siente el centro del mundo, ve al resto como «lo otro» y se plantea una vida en función de esas directrices. Es este un proyecto muy típico del pensamiento revolucionario adolescente, reflejado en el Raskólnikov dostoievskiano y abanderado filosóficamente por Nietzsche y su superhombre. Así, en un primer momento, la racionalidad humana, que comienza plantearse el porqué de las cosas que la sociedad le impone, se forja una idea sobre el libre albedrío totalmente egoísta y egotista. Este es, como decimos, el primer paso; aunque algunas personas no llegan siquiera a darlo (ese hombre masa por excelencia, antagónico a las mentalidades individualistas). Por otro lado, muchos de los que dan ese primer paso se quedan en él para siempre. Y estos serán los caracteres antisociales, antiheroicos, criminales... los inadaptados, en cualquier caso. Estos individuos, que nunca se reconciliarán con la sociedad, suelen acabar enfrentándose a ella y, por supuesto, despreciados, agredidos, acusados, encerrados o, incluso, condenados a muerte según el grado de radicalidad con el que se hayan opuesto a la masa.

Sólo unos cuantos lograrán encumbrarse por encima de la masa, serán los llamados héroes (diferenciados de los antihéroes fundamentalmente por el éxito que hayan tenido en sus gestas). Ese deseo de convertirse en héroe, el deseo de ganar honra es el que lleva a Ignacio de Loyola a Pamplona a batallar contra los franceses en 1521, es el que hace que quede malherido y, realmente, es el que impulsa a este hombre a dar el salto existencial que cambió su vida.

Es por todos conocido que, tras este suceso, queda postrado durante una larga convalecencia y, casi por mera casualidad, descubre la Vida de los Santos y el Vita Christi, donde comenzará a contemplar la importancia del amor para una existencia plena. La libertad aquí ya no se basa en un individualismo, sino que comienza a verse desde un punto de vista plural. Este sentimiento hará al sujeto cambiar de proyectos vitales y, en consecuencia, buscar la mejora de la sociedad para que progrese, se desarrolle y siga protegiendo a todos sus ciudadanos. Es el reflejo de lo que Dostoievski quiere exponer con el amor global. Aunque, como hemos mencionado anteriormente, nuestro autor propondrá el enamoramiento hacia otra persona como un paso intermedio. Si bien San Ignacio comenta que sintió el amor hacia cierta señora ${ }^{14}$ mientras estaba convaleciente, en su caso no tendrá esta relevancia (o, al menos, eso

13 Ignacio De Loyola, El relato del peregrino. Autobiografía de Ignacio de Loyola, Ediciones Mensajero, Bilbao, 1991, p. 13

14 Cfr. Ignacio De Loyola, Autobiografía, p. 15. Según algunos estudios, esta señora pudo ser Catalina de Austria o Germana de Foix, segunda mujer de Fernando el Católico, entre otras. 
parece). De cualquier manera, parece evidente que Ignacio sintió en lo más profundo de su ser la sensación del enamoramiento hacia otra persona, y que esto ocurrió en un momento crucial de su desarrollo existencial.

El nivel basado en el amor a la humanidad, estará por encima del amor hacia otra persona en concreto. Cuando uno llega a experimentar ese amor (como es el caso de Aliosha Karamázov), logra ver a la humanidad como un Nosotros. Se maximiza así el alcance que tenía esa llegada al nosotros (con minúsculas) expuesta en el nivel anterior. Al experimentar ese Nosotros (con mayúsculas), el individuo obvia los conceptos de lo ajeno y lo propio, se socializa en su grado máximo, se vuelve comunitario por definición y apuesta por los demás al mismo nivel que por sí mismo. Este es el súmmum en lo que a existencia humana puede definir Dostoievski ${ }^{15}$. Únicamente a estos hombres podría encomendárseles el perfeccionamiento de la humanidad. Sólo desde el amor global puede experimentarse la verdadera libertad. El amor será, como afirma Buytendijk, la única condición de posibilidad para la abolición de todo dolor y de todo pecado ${ }^{16}$. El resto será mera invención utilitaria.

$\mathrm{Si}$ el hombre alcanzara esa existencia basada en el Nosotros comunitario, lograría simultáneamente alcanzar una autenticidad existencial desconocida aún para la humanidad. Esto es lo que busca también la ética de los jesuitas. Por ello, la búsqueda del amor general será el punto de partida de una existencia verdadera, de la existencia del hombre pleno ${ }^{17}$. Y este hombre pleno, superior,

15 Lauth, Reinhard, Dostoievski, su siglo y el nuestro, trad. Alberto Ciria, Prohom Edicions, Barcelona: «La comprensión práctica viviente de la exigencia de amar «convence» del vínculo universal y de la vida eterna. En el amor se vuelve posible ver la verdad. Este pensamiento fundamental transciende, como la más profunda convicción del autor, a las ideas de los diversos personajes que de un modo u otro son llevados a meditar sobre él. La manera como lo realizan determina su destino vital. Las voces supuestamente independientes en la obra de Dostoievski se muestran, a través del pensamiento fundamental que actúa con independencia de ellas, como voces de una sinfonía vinculadas y subordinadas al desarrollo, a saber, de la sinfonía del gran acontecer mundial en el que este pensamiento fundamental se confirma en su verdad» (p. 222).

16 BuYtendiJK, op. cit.: «El misterio de estas personas 'insólitas' de las novelas de Dostoievski es el misterio de las más extremas posibilidades. Su existencia llena de inquietud y de nostalgia nos indica un nuevo mundo, una tierra firme, a la que se llega tras el vagabundeo angustioso por el mundo de los afanes, en un Sein zum Tode ('ser para la muerte'). Cuando se entra en esta tierra firme, 'todos los hombres se amarán entre sí y ya no habrá pecado ni sufrimiento', dice Dostoievski. Quien está familiarizado con la obra de Dostoievski sabe que este pensamiento de la abolición de todo dolor y de todo pecado por obra del amor, no es una enunciación teórico-ética, sino una idea, que solamente es verdad cuando está encarnada en la realidad humana, tal como ésta aparece en el 'torbellino' de la existencia. En sus novelas la violencia de este torbellino se convierte en nuestra posibilidad» (p. 48).

17 En El sueño de un hombre ridículo podemos encontrar muchas de estas ideas basadas en el hombre pleno, eso sí, presentadas paradójicamente como parte del sueño de un «hombre ridículo»: «Ya entonces me di cuenta al instante de que en absoluto lograría comprenderlos en muchos aspectos; a mí, como ruso contemporáneo y progresista, como triste petersburgués, me parecía inconcebible, por ejemplo, que ellos, sabiendo tanto, no tuvieran nuestra ciencia. Pero enseguida comprendí que sus conocimientos se llenaban y alimentaban de pretensiones 
será el que logre afirmar su voluntad, porque su voluntad será siempre beneficiosa para los demás. La voluntad del hombre pleno es siempre beneficiosa para los demás porque está hecha desde ese enamoramiento hacia la humanidad. Y, si esto es así, si la humanidad en bloque consiguiera convertirse en un conjunto sincronizado de hombres plenos, el mismo hombre se haría bueno a sí mismo.

Esa abolición de todo dolor y de todo pecado por obra del amor de la que habla Buytendijk en el texto que hemos citado anteriormente puede dar a entender que, como incluso propone Dostoievski en Los demonios, si el hombre consiguiera hacer bueno al hombre, si pudiera enseñar a los mismos hombres que todos son buenos, se convertiría en un Hombre-Dios o, lo que es lo mismo, en un superhombre. Pero nuestro autor conoce perfectamente la impracticabilidad material de su pensamiento (como ya nos adelantaran Platón, Aristóteles o Tomás de Aquino). El hombre experimenta de manera muy profunda su tendencia hacia el mal, y esta tendencia es irrenunciable. Por ello esta idea del amor global se convertirá en un eterno intento mediante el cual el ser humano deberá perfeccionarse a sí mismo de manera individual, progresiva y constante.

Lo que marcará el horizonte existencial en el pensamiento de Dostoievski será una constante búsqueda de la Verdad (concepto básico en la filosofía occidental desde el mismo Platón). Y esa tarea sólo será posible a través de otra búsqueda: la del amor global, que dotará al ser humano de una existencia verdadera (concepto sorprendentemente similar al fruto de la epifanía ignaciana $)^{18}$. Sólo desde el intento de una existencia auténtica, será el hombre capaz de vislumbrar esa Verdad que tanto interesaba a nuestro autor. Pero esto no es una meta alcanzable, sino un camino constante en el que no se puede cesar de andar. Sólo podemos tener constancia de la existencia de esa plenitud, según Dostoievski, asomándonos al reflejo de perfección que nos proporciona el amor infinito que supone la idea de Dios. Y esta idea, como parece evidente, tomará cuerpo en grado sumo en la figura de Cristo.

distintas de las que nosotros teníamos en la Tierra, y que sus aspiraciones también eran completamente diferentes. No deseaban nada y estaban tranquilos, no ansiaban conocer la vida como lo hacemos nosotros, porque su vida había alcanzado toda la plenitud. Sin embargo, sus conocimientos eran más profundos y elevados que los de nuestra ciencia, pues ésta busca explicar la vida, tendiendo a su vez a adquirir conciencia de ella con el fin de enseñar a vivir a otros; ellos, por el contrario, sabían cómo habían de vivir incluso sin la ciencia, y yo lo entendí, pero no conseguí comprender sus conocimientos» (p. 490).

18 También en El sueño de un hombre ridículo, podemos ver un reflejo del ansia dostoievskiana por la búsqueda de la Verdad como camino para conseguir la plenitud humana. El protagonista, tras despertar de ese sueño en el que ha conocido al hombre pleno, a la humanidad carente de vicios, afirma: «Mientras permanecía de pie recobrando el sentido, de pronto centelleó anti mí el revólver, preparado y cargado; pero al instante lo aparté. ¡Oh! ¡Ahora sólo quería vivir y vivir! Alcé las manos y clamé por la Verdad eterna. No clamé, sino que lloré; el asombro, el incalculable asombro, elevaba todo mi ser. ¡Sí! ¡Quería vivir y predicar! Decidí dedicarme a la predicación en aquel mismo instante y, lógicamente, para el resto de mi vida. Quería predicar, lo quería. ¿Y qué iba a predicar? ¡Pues la Verdad, ya que la había visto con mis propios ojos y había descubierto toda su gloria!» (p. 496). 


\section{Dostoievski y CRISTO}

En Dostoievski, todo el entramado existencial tomará su sentido completamente a través de la idea de Dios. En el autor ruso, la fe fundamenta a la razón y viceversa. Pero no va a entregar meramente su razón a los libres designios de su fe, sino que hará un complicado ejercicio de revisión de sus creencias más firmes para intentar comprender a aquéllos que experimentan la existencia desde unos planos completamente distintos. Dostoievski es el autor que se pone en el lugar del prójimo a través de sus personajes. Revisa los límites de la existencia para conseguir experimentar las diferentes maneras de estar en el mundo y comprenderlas así de una manera más profunda.

Y de esta revisión concluirá una poderosa autoafirmación de sus previas creencias. Con el ejercicio literario-filosófico que lleva a cabo a lo largo de toda su carrera literaria, nuestro autor consigue dar más solidez aún a sus creencias que, a sus ojos, serán más fuertes y más válidas que las meras creencias basadas simplemente en la $\mathrm{fe}^{19}$. Dostoievski es el autor que se enorgullece de haber puesto en tela de juicio sus creencias, de haber revisado su fe bajando a los confines más subterráneos del alma humana, y habiendo regresado con éxito, con sus ideas poderosamente reforzadas.

Podemos leer en Los demonios:

«Toda la ley de la existencia humana consiste en que el hombre es siempre capaz de reverenciar lo infinitamente grande. Si al hombre se le priva de lo infinitamente grande, se negará a seguir viviendo y morirá desesperado. Lo infinito y lo eterno le son tan necesarios como este pequeño planeta en que habita... Amigos míos, amigos todos, todos: ¡Viva la Gran Idea! ¡La eterna, infinita Idea! Todo hombre, sea quien fuere, debe inclinarse ante lo que es la Gran Idea. Hasta el hombre más necio necesita algo grande. Petrusha... ¡Oh, cómo me gustaría verlos a todos! ¡No saben, no saben que también en ellos reside la Gran Idea! ${ }^{20}$.

Las bases del ideario existencial de Dostoievski se fundamentan claramente en las mismas ideas que defiende el cristianismo occidental y, en especial, la ética jesuítica $^{21}$. Sus obras pueden considerarse como una manera distinta de ver el

19 Recordemos los textos en los que compara su fe con la de otros, afirmando con cierta arrogancia que nadie puede darle lecciones al respecto. Por ejemplo, en Del Dostoievski inédito. Pensamientos anotados, se recoge: «Los tunantes me dan burla por mi, al parecer, inculta y reaccionaria creencia en Dios. Esos imbéciles no han podido en la vida ni siquiera soñar una negación de Dios cual la que se expresa en mi Gran Inquisidor y todo el capítulo que lo precede y a la que responde el libro entero. Si yo creo en Dios, no creo a la manera de los tontos (como un fanático). ¡Y esos quieren darme lecciones y se ríen de mis cortos alcances! Esos estúpidos no han podido soñar siquiera con un poder de negación como el que yo he demostrado. ¡Y quieren darme lecciones!» (p. 706).

20 Dostoievski, Los demonios, p. 813.

21 LaUth, R., op. cit.: «En las exposiciones se desliza a menudo una polémica religiosa contra la ortodoxia exclusiva, junto con una apología de la Iglesia occidental. Pero querer resolver problemas concretos en la obra de Dostoievski sigue siendo una empresa 
mismo contenido filosófico. Tiene razón Lauth al hablar de la religiosidad de nuestro autor, aunque nos encontremos un feroz ataque a la religión en muchos de sus textos que podrían hacernos dudar ${ }^{22}$. La religiosidad de Dostoievski está clara, hay muchos textos (periodísticos, de opinión, epistolario...) en los que la patentiza; pero en muchas ocasiones no quiere mostrar esas ideas en sus obras de ficción, sino las contrarias. Dostoievski escribe unas novelas basadas en el hombre, no en Dios; por eso muchos críticos se pierden a la hora de catalogar al autor y por eso, autores como Nietzsche, pueden llegar a alabarle.

Indudablemente, nuestro autor está totalmente imbuido por el cristianismo y hace una defensa acérrima de este cuando escribe textos como el referente al discurso de Birchov ${ }^{23}$. Dostoievski cree que todo lo que ocurre en el hombre y

ardua y necesariamente fragmentada mientras no se sea capaz de captar por entero su emplazamiento en la economía global de su visión del mundo, y mientras no se hayan aclarado suficientemente los presupuestos antropológicos, metodológicos y psicológicos. Dostoievski está inequívocamente en el suelo del cristianismo ortodoxo; acerca de ello no puede caberle al conocedor ninguna duda. Sin embargo, él mismo sobreestima la concordancia de su doctrina con la de la ortodoxia, mientras que rechaza decididamente el catolicismo occidental (al que, sin saberlo, tiene pese a todo mucho que agradecerle) y el protestantismo. [...] En tiempos futuros se demostrará que Dostoievski ocupa en la filosofía de la religión cristiana una posición tan originaria como San Agustín, Tomás de Aquino o Lutero» (pp. 24-26).

22 Ibid.: «Hay un motivo profundo por el cual en la obra de Dostoievski se encuentra un ataque radical a la fe en Dios, al convencimiento en el sentido de la existencia y a los conceptos morales fundamentales, de modo que el poeta poco antes del final de su vida pudo escribir en su cuaderno de notas: "Ni siquiera en Europa hay ni ha habido jamás una expresión de ateísmo tan poderosa». Él necesitaba el ateísmo en su forma más peligrosa para purificar de toda mácula su fe cristiana. Así vemos cómo el pensamiento de Dostoievski se va alzando antitéticamente hacia una confrontación única entre el ateísmo y la fe en Cristo. Ahí se ha arriesgado justamente a los problemas que de ordinario suele hábilmente eludir: el sentido del sufrimiento de seres inocentes, la eternidad del infierno, el hecho del mal, etc. Él es el creador de la teoría del hombre superior, del mito político, del existencialismo de la angustia (junto a Kierkegaard) y del nihilismo religioso, y es consciente de que aquí se ha atrevido a pensar hasta el fondo las ideas que sus contemporáneos y predecesores pensaron sólo a medias. Él necesita de todos estos proyectos de una vida sin Dios, todas estas acometidas contra el sentido de la fe, porque no quiere fundamentar su convencimiento positivo sobre una base oscilante. Si le seguimos paso a paso a lo largo de toda su obra, la contemplación de su agonía y de su búsqueda provoca realmente una transformación en nuestra alma, que es guiada a través de un purgatorio de las dudas, donde ella purifica su relación con Dios y se ve inapelablemente obligada a rendir cuentas sobre los últimos presupuestos de su fe y su querer» (p. 29).

23 Dostorevski, F. M., o. c., Del Dostoievski inédito, Pensamientos anotados: "La diferencia entre nosotros y Europa. El Estado es una sociedad eminentemente cristiana y tiene propensión a convertirse en Iglesia. En Europa es a la inversa (una de las profundas diferencias entre nosotros y Europa). Véase el discurso de Birchov (Novoye Vremia número 1745, 6 de enero de 1881). Dice Birchov que el Estado es, ante todo, una sociedad exenta de religión y de cristianismo. Tal sucede en Francia (Gambetta). Nuestros lechuguinos se han dado prisa a apoderarse de la fórmula de Occidente e inscribirla en su catecismo. Pero aquí, en el pueblo ruso, todo eso resulta enteramente extraño. Teme Birchov que los cristianos pudieran sentir enseguida el deseo de aniquilar a los no cristianos. Por el contrario, el espíritu del verdadero cristianismo es... la absoluta libertad de creencias. Cree espontáneamente: he ahí nuestra fórmula. La salvación no descendió para nosotros de la cruz porque no 
todas las convicciones morales de este son fruto de Cristo, no de ningún tipo de lógica ${ }^{24}$. Pese a ello, piensa que la ciencia debe estudiar la religión y sus fundamentos morales, ya que, en esta, según él, reside la Verdad. Como vemos en la nota al pie, en este texto vuelve a reiterar el autor su fe en Cristo como fruto de un gran esfuerzo analítico, un duro ejercicio de negación de la fe que le ha llevado a poder afirmarla sin ningún tipo de reparo ${ }^{25}$.

E, igualmente, argumentará en contra del ateísmo, por muy inteligente y humanitario que se presente en un principio, considerándolo como extremadamente nocivo y peligroso para la humanidad ${ }^{26}$. El concepto de Dios será el que dé sentido a todo el edificio argumentativo dostoievskiano. Su idea de amor global no queda meramente en ese eterno intento del que hablábamos antes, sino que lo aplica a un sentido infinito a través de la idea de Dios.

$\mathrm{Y}$ es que, si afirmara, meramente, que la tarea del hombre es la de buscar su plenitud en un constante esfuerzo por conseguir un amor global, Dostoievski sentiría que la tarea siempre quedaría incompleta, sería un constante y eterno fracaso. El hombre, ser finito, jamás sería capaz de hacerse pleno, y debería basar su plenitud en ese eterno intento (muy al estilo del virtuosismo aristotélico). Pero al incluir a Dios en la ecuación comenzamos a obtener resultados infinitos.

quería imponerse mediante un prodigio exterior, sino que precisamente deseaba la libertad de creencias. Tal es el espíritu del cristianismo y también de nuestro pueblo. Si existen desviaciones, lo lamentamos» (p. 704).

24 Ibíd.: «El poderoso hecho de la aparición de Cristo en la Tierra y todo lo demás requiere también, a mi juicio, una elaboración científica. La ciencia no puede considerar como indigno de ella el investigar la importancia de la religión en la Humanidad, aunque sólo fuere habida cuenta del hecho histórico que sorprende por su continuidad y persistencia. [...] Creo en Cristo y proclamo mi fe, no como un niño, pues mi hosanna ha pasado por el purgatorio de la duda, como en mi última novela dice de sí mismo el diablo» (p. 709).

25 Esta particular visión del cristianismo será objeto de duras críticas por parte de los detractores de nuestro autor. Argumentará Nabokov: «Voy a citarles una observación muy oportuna de Mirski acerca de Dostoyevski: «Su cristianismo... es de un género muy dudoso... Era una formación espiritual más o menos superficial, que sería arriesgado identificar con el cristianismo auténtico». Si a esto añadimos que reclamaba para sí el carácter de intérprete genuino del cristianismo ortodoxo, y que para desatar todo nudo psicológico o psicopático remite ineluctablemente a Cristo, o más bien a su personal interpretación de Cristo, y a la santa Iglesia ortodoxa, comprenderemos mejor el lado verdaderamente irritante de Dostoyevski como «filósofo»» (Curso de literatura rusa, trad. María Luisa Balseiro, Ediciones B, Barcelona, p. 244).

26 Dostoievsкi, F. M., Diario de un escritor: «Puede que me objeten que esos señores no enseñan nada malo; que Strauss, por ejemplo, si bien odia el cristianismo y ha consagrado su vida a befarse de él y escupirle, ha deificado al mismo tiempo a la Humanidad en bloque, siendo sus teorías de lo más noble y sublime que pueda imaginarse. Es muy posible que todo eso sea así, y que las miras de todos los actuales caudillos del pensamiento progresivo europeo sean filantrópicas y sublimes. Pero a mí, en cambio, me parece indudable lo siguiente: que si a los referidos excelsos maestros se les diese plena posibilidad de destruir la sociedad vieja y fundar una nueva..., sobrevendrían tales tinieblas, tal caos, algo hasta tal punto brutal, ciego e inhumano, que todo el edificio se vendría abajo entre las maldiciones de los hombres, aun antes de estar terminado. Cuando la razón humana da de lado a Cristo, puede llegar a resultados sorprendentes» (p. 218). 
Cuando el hombre es capaz de elevar su amor a Dios, está haciéndose parte de una idea infinita de amor. Por ello, la luz de guía en el camino hacia la Verdad será, ineludiblemente, Dios. Una vez que nuestro autor ha conseguido vislumbrar un conocimiento de la Verdad a través de sus personajes, necesitará de ese elemento infinito para mantener dicha Verdad, para hacerla eterna. Y aquí residirá realmente el éxito de la consecución de plenitud existencial. Esta plenitud, como ya hemos anunciado, tendrá su ejemplo más significativo en Cristo.

Uno de los pensadores que más han profundizado en el asunto de la concepción dostoievskiana de Dios, es el ya mencionado Lauth. Para Lauth, la piedra angular de la filosofía de Dostoievski residirá precisamente en su idea de Dios. Y afirma que el genio ruso llegó a la idea de Dios a través de distintas reflexiones. Veremos las propuestas más importantes a continuación:

Para Lauth, Dostoievski vio en Jesucristo la perfección moral encarnada en hombre. Jesucristo es el hombre pleno, el que ama al hombre como parte de sí mismo, como propio. De este modo, encontramos en Cristo una persona con una perfección moral jamás alcanzada. Y esto es así porque Cristo es Dios hecho hombre; de este modo, su amor pasa de ser un amor finito, humano, caducable, a ser un amor infinito y realmente global. En esta línea, afirma Lauth que toda la ley de Cristo consiste en la exhortación a amar. Según este autor, con su vida y su muerte, Cristo enseña a la humanidad por primera vez el comportamiento moral puro. Es el ejemplo que ya mencionábamos de la total entrega por el infinito y sincero amor hacia el resto de existencias. Así, tenemos en esta figura el ejemplo más claro de lo que Dostoievski pretende encontrar en el hombre pleno, fijando en este punto sus ideas morales supremas.

Nos cuenta Lauth que Jesucristo superó completamente su yo, entregándolo del todo y sin reservas a todos y cada uno. E hizo esto, dice, porque tenía en sí el amor supremo, o lo que es lo mismo, la gracia divina. El amor de Cristo no es un amor equiparable al amor supremo que pueden desarrollar otros hombres, como por ejemplo los santos. Y esto es porque los santos, aunque hombres excelsos, no dejan de ser hombres; están en ese escalón de eterno intento, de búsqueda constante, de perpetuo perfeccionamiento. El amor del santo, el mismo que siente Ignacio de Loyola, será el grado máximo al que un hombre puede llegar a través de todo el proceso que hemos expuesto a lo largo de este trabajo. Sin embargo, la figura de Cristo representa al infinito que se encarna en hombre, y que es capaz de amar de manera infinita. Y, si bien el hombre no tiene la posibilidad terrenal de llegar a ese nivel excelso, sí tendrá el soporte de esa guía de perfección moral y de comunión con el infinito que otorga el conocimiento cristiano. Cristo es la imagen especular de Dios en la Tierra.

De este modo, afirmará Lauth que fue Cristo quien hizo que la humanidad vislumbrara en sí lo divino, el amor y la verdad de Dios. Fue él quien consumó la obra de la revelación, poniendo así a la humanidad para todos los tiempos en unión inmediata con Dios a través de la unión consigo mismo. Cristo es, a ojos de Lauth, quien abre la posibilidad al hombre para que pueda realizar lo que Dostoievski propone: encontrar el Reino de los cielos en sí mismo, a través del perfeccionamiento moral. 
Todo esto influirá de una manera profunda en un autor que sigue poniendo en tela de juicio su fe, dirimiendo siempre racionalmente su alcance. De hecho, el concepto en sí es tan poderoso para Dostoievski, que llega a hacérsele irrelevante que la existencia de Cristo haya sido real o ficticia. Incluso llegará a afirmar que si alguien le hubiera demostrado que Cristo está fuera de la verdad, y si realmente se hubiera establecido que la verdad está fuera de Cristo, entonces habría preferido quedarse con Cristo antes que con la verdad. Y esto, dice Lauth, no es fruto de un empecinamiento ni de un partidismo ciego de Dostoievski, sino la señal de que este autor concede por principio al pensamiento del sentido y del valor una prioridad sobre la experiencia empírica. El hecho de la existencia real de Cristo es poco relevante, pues el mero concepto ya sirve como ejemplo para exponer la idea de hombre pleno que Dostoievski defiende de manera convencida. Así, todos los hombres son versiones incompletas de Cristo, que llegará a ser plenamente en ellos cuando estos alcancen la perfección.

En esta línea, en sus novelas podrán encontrarse hombres religiosos como personajes actuantes que asumirán cada vez espacios más amplios dentro del texto. Como ejemplos propondrá Lauth al peregrino Makar Ivanovich en El adolescente o el stárets Zosima en Los hermanos Karamázov, aunque le cautivarían aún más los hombres simples y sencillos del pueblo en los que se mostraba la religiosidad. En todo caso, los santos serán el nivel máximo al que el ser humano puede llegar ya que están unidos del modo más íntimo con toda la humanidad mediante la síntesis del amor. Los santos son tales precisamente por su amor a Dios y a los hombres, y esta es la más excelsa existencia a la que un ser humano podrá optar.

También será relevante para Lauth la figura de Cristo como garante de la voluntad de vida humana. La voluntad de vida (que se expresa en la pulsión de Eros, en el sentimiento amoroso, en la voluntad creadora) sólo puede encontrar su pleno cumplimiento en una persona infinita, perfecta y siempre amorosa y digna de amar: o sea, en Dios. Igualmente, la idea de perfección moral (como ya hemos visto anteriormente), llevará inequívocamente a ojos de Lauth hacia el concepto divino. La esencia de Dios se hace patente a través de los hombres morales, según su grado de perfección, y de una manera perfecta en Cristo. A través de Cristo, como ya hemos visto, podemos amar a Dios como persona individual y tenemos abierta la posibilidad de alcanzar la finalidad suprema de la ley moral y de la voluntad de vida.

En definitiva, podemos ver claramente que la idea de la divinidad en Dostoievski toma forma, de manera preeminente, en la figura de Jesucristo. Y esta será la idea que guíe, sin lugar a dudas, la obra de nuestro autor, aunque no podamos ver un personaje que lo encarne. Se ha pretendido, en alguna ocasión, asemejar la figura del Príncipe Mischkin, de El Idiota, a la de Cristo. Aunque en esto tenemos que objetar, con Lauth y otros, que no puede afirmarse claramente $^{27}$. Es cierto que nuestro autor tuvo en mente el modelo de Cristo o

27 Dostoievski, F. M., o. c., Prólogo a El Idiota de R. Cansinos-Assens: «El príncipe Mischkin es el primer paso para la creación de Aléksieyi Karamázov, del hombre perfecto, adánico, 
del hombre pleno cuando creó este personaje, pero el sentido de su plenitud (si es que la tiene) no está en sí mismo, sino en el conjunto de la obra y en su relación con todos los personajes. Por esto afirmamos que no podemos encontrar en la obra de Dostoievski una explicitación de su ideario religioso. Y este hecho es el que puede confundir a algún lector parcial o tendencioso. La religiosidad de Dostoievski se patentiza estudiando su vida y el conjunto de sus escritos, ficticios y no ficticios. Sólo de esta forma podemos encontrar esa relación entre el autor y un Dios encarnado en Cristo, que realmente será su guía existencial, pero que no lo es de muchos de sus personajes que mostrarán sus negaciones de una manera abrumadora y realista.

\section{Conclusión.}

Como hemos podido observar, el eslavófilo Dostoievski presenta un proyecto existencial prácticamente idéntico al presentado por el cristianismo de Occidente. Coincidiendo con lo que afirmaba Lauth, Dostoievski tiene que agradecer a Occidente mucho más de lo que, en principio, él mismo cree, tanto en el ámbito religioso como en el filosófico. La base subyacente de su obra al completo se enfoca hacia la búsqueda de ese hombre pleno que sólo se alcanzará a través de la figura de Cristo, como muestra de luminosidad basada en el amor.

Por ello, es injusto tomar a Dostoievski meramente como el pensador del sufrimiento (al igual que es injusto tomar al cristianismo en general como el propugnador de la resignación ante el dolor y de la mera esperanza en una vida mejor más allá de la terrenal). Ambas posturas llegan mucho más lejos: la existencia del hombre pleno se basará en cambiar lo negativo, en hacer mejor lo terreno, en irradiar de luz a la humanidad siempre desde la perspectiva de una comunidad, de un todo con un mismo fin. Y Cristo será la guía, el enlace con lo trascendente, el fuego que enciende otros fuegos.

Desconocemos si Dostoievski tuvo constancia de la vida de Ignacio de Loyola, pero las coincidencias entre la vida del santo y la propuesta existencial del autor ruso resultan, en cualquier caso, curiosas. El padre de la Compañía de Jesús podría haber sido perfectamente el prototipo de lo que Dostoievski quiso pintar con su stárets Zósima o con Aliosha Karamázov: personajes basados en la luz más que en

\footnotetext{
inocente, que Dostoyevski no llegará a darnos por completo, como tampoco nos dará la figura acabada del «gran pecador». Mischkin, como Aléksieyi Karamázov, pertenecen al mundo evangélico, y por eso ejercen su catequesis entre la delicada y sutil pedagogía [...] Mischkin es un personaje literario, un héroe de poema, un fantasma, una proyección de Dostoyevski y, en definitiva, un argumento contra Raskólnikov [...] Pero en este sentido cabe reprocharle a su creador que no haya sabido presentarnos una encarnación más brillante y afirmativa que la de este pobre espíritu, adornado de virtudes pasivas, aunque tal reproche sería también arbitrario, ya que Mischkin, por la ley misma de su vida, tiene que ser así: una criatura inactiva y ociosa, «un divino gandul»». Podemos afirmar, con Cansinos-Assens, que no hay un personaje que alcance esa plenitud existencial que propone Dostoievski como ideal de vida. La manera más perfecta será la representada por personajes como Tichon o Zosima, hombres santos.
} 
la sombra, en la acción más que en la mera contemplación, personajes que saben que no hay verdadera salvación si no se da en comunidad con los demás, que animan a mirar de otra manera y que invitan a llenarse de vida. Eso fue Ignacio de Loyola (y es el legado que permanece hoy día), y eso fue, también, Dostoievski.

\section{BIBLIOGRAFÍA}

Berdiaev, N., El espíritu de Dostoyevski, trad. Olga Trankova, Editorial Nuevo Inicio, Granada, 2008.

BuYTENDIJK, Fr. J. J., La psicología de la novela. Estudios sobre Dostoievski, trad. Fernando Vela, Ediciones Carlos Lohlé, Buenos Aires, 1961.

Carrara, A., L'epopea cristiana del popolo russo. Temi di teologia nei Frateli Karamazov, Vita e Pensiero, Milano, 1990.

Carroll, J., La fuga dal palazzo di cristallo. Contro Stirner, Nietzshe, Dostoiewski e l'anarco-psicologia, Valdi, Roma, 1981.

CASCARDI, A., The bounds of reason. Cervantes, Dostoevsky, Flaubert, Columbia University Press, Irvintong, 1986.

CASSEDy, Steven, Dostoevsky's Religion, Standford University Press, Standford, 2005.

Chestov, León, La Filosofía de la Tragedia. Dostoievski y Nietzsche, trad. Isidro Herrera Baquero y Alejandro del Río Herrmann, Emecé Editores, Buenos Aires, 1949.

CicovacKi, Predrag, Dostoevsky and the Affirmation of Life, St. Augustine's Press, Chicago, 2008.

CRISTaldi, G., Dostoevskij o la scommessa della fede, Vita e Pensiero, Milano, 1989.

DaLTon, E., Unconscious structure in The Idiot. A study in literature and psychoanalysis, Princeton University Press, Princeton, 1979.

De Loyola, Ignacio, Ejercicios Espirituales, Editorial Sal Terrae, Santander, 1990.

De Loyola, Ignacio, El relato del peregrino. Autobiografía de Ignacio de Loyola, Ediciones Mensajero, Bilbao, 1991.

Díaz Márouez, M., Fiódor Mijáilovich Dostoievski: existencia, sociedad y verdad, Universidad de Sevilla, Sevilla, 2011.

Díaz Márouez, M., La luz en Dostoievski, Ediciones Casas, Sevilla, 2012.

Dostorevsкi, F. M., Apuntes del subsuelo, trad. Juan López-Morillas, Alianza Editorial, Madrid, 2002.

Dostoievsкi, F. M., Cuentos, trad. Bela Martinova, Ediciones Siruela, S. A., Barcelona, 2009.

Dostoievsкi, F. M., El Doble, trad. Juan López-Morillas, Alianza Editorial, Madrid, 2000.

Dostoievsкi, F. M., Los demonios, trad. Juan López- Morillas, Alianza Editorial, Madrid, 2007.

Dostoievski, F. M., Los hermanos Karamázov, trad. Augusto Vidal, Cátedra Letras Universales, Madrid, 2000.

Dostoievski, F. M., Obras Completas (Edición en 3 tomos), trad. Rafael Cansinos-Assens, Aguilar, Madrid, 1992.

Dostoyevskis, F., - Dostoevskaja A. J. Corrispondenza (1886-1870), Salmon L., Ed. Il Melangolo, 1987.

Достоевский, Ф. М., Собранию сочинений в десяти томах, Москва, Художественная литература, 1957.

ECHEVERRÍA, J., El superhombre y el idiota. Reflexiones sobre Nietzsche y Dostoyevski, Diálogos (16), n. ${ }^{\circ}$ 38, Río Piedras (Puerto Rico), 1981. 
Evdokimov, P., Dostoïevsky et le probléme du mal, Desclée de Brouwer, Paris, 1978.

Guardini, Romano, El Universo Religioso de Dostoyevski, trad. Alberto Luis Bixio, Emecé Editores, Buenos Aires, 1954.

Hallet Carr, Edward, Dostoievski, 1821-1881: lectura crítico-biográfica, trad. Arturo Licetti, Laia, Barcelona, 1972.

Hessen, S., Il bene e il male in Fëdor M. Dostoevskij, Armando, Roma, 1980.

Hita Jiménez, José Antonio, Nueva visión de la obra de Dostoievski, Editorial Universidad de Granada, Granada, 2003.

Hubben, William, Dostoevsky, Kierkegaard, Nietzsche and Kafka, Ed. Touchstone, New York, 1977.

Ivanov, Vyacheslav I., A Study in Dostoevsky: Freedom and the Tragic Life, The Noonday Press, New York, 1970.

Kaufmann, Walter, Existentialism from Dostoevsky to Sartre, Penguin Group, New York, 1989.

Kuetsaa, G., Dostoyevski. La vida de un escritor, trad. A. Leal, Vergara, Buenos Aires, 1989.

KRIsteva, J., "Dostoievski, una poética del perdón». El perdón. Quebrar la deuda y el olvido, Cátedra, Madrid, 1992.

Lauth, Reinhard, Dostoievski, su siglo y el nuestro, trad. Alberto Ciria, Prohom Edicions, Barcelona, 2005.

McReynolds, Susan, Dostoevsky and Schiller: National Renewal Through Aesthetic Education, en Philosophy and Literature, Vol. 28, Número 2, Baltimore, 2004.

Madaule, C., Fëdor Dostoïevskij, Borda, Torino, 1965.

Madaule, J., Dostoïevski, Editions Universitaires, Paris, 1956.

Miller, R. F., Dostoievski, l'intuitif, le croyant, le poète, Albien Michel, París, 1954.

Naвокоv, V., Curso de literatura rusa, trad. María Luisa Balseiro, Ediciones B, Barcelona, 2009.

Pareyson, L., Dostoevskij. Filosofia, romanzo ed esperienza religiosa, Einaudi, Torino, 1993.

Rolland, J., Dostoevskij e la questione dell'altro, Jaca Book, Milano, 1990.

RuDNICKI, Adolf, Dostö̈evski ou l'amour de l'homme, Folle avoine, Bédée, 1994.

Scalan, James P., Dostoevsky, the thinker, Cornell University Press, New York, 2002.

Serrano Poncela, Segundo, Estudios sobre Dostoievski, Ediciones de la Universidad Central de Venezuela, 1968.

Stellino, Paolo, El descubrimiento de Dostoievski por parte de Nietzsche, en: Contrastes. Revista Internacional de Filosofía, vol. XIII, 2008.

Troyat, Henri, Dostoyevski, trad. Irene Andresco, Ed. Destino, Barcelona, 1946.

VIDAL, A., Dostoyevski. El hombre y el artista, Círculo de lectores, Barcelona, 1990.

VV. AA., Dostoevsky and the Christian tradition, Cambridge University Press, New York, 2001.

VV. AA., L'histoire cachée du nihilisme: Jacobi, Dostö̈evski, Heidegger, Nietzsche, La Fabrique éditions, Paris, 2008.

Williams, Rowan, Dostoevsky: language, faith and fiction, Baylor University Press, Waco, 2008 .

Fundación SAFA, Andalucía

Manuel Díaz Márouez

manueldiaz@fundacionsafa.es

www.manueldiazmarquez.es

[Artículo aprobado para publicación en diciembre de 2016] 